\title{
Incorporation of nanoclay into field latex to develop nanoclay filled dry rubber compounds
}

\author{
S. Jayaraj", S.M. Egodage and S. Walpalage \\ Department of Chemical and Process Engineering, Faculty of Engineering, University of Moratuwa, Katubedda, Moratuwa.
}

Revised: 21 November 2016; Accepted: 08 December 2016

\begin{abstract}
Two types of nanoclay filled dry rubber compounds were prepared by incorporating sodium montmorillonite (MMT) into natural rubber (NR) at latex stage. Nanoclay filled rubber sheets prepared by acid co-coagulation (ACC) and acid free co-coagulation (AFCC) rubber production methods were milled and compounded to develop nanoclay filled dry rubber compounds. The MMT loading was varied from 0 to $20 \mathrm{phr}$. Both the above methods are not used as filler incorporation methods in dry rubber industry. AFCC rubber vulcanisates, compared to ACC rubber vulcanisates showed improved mechanical properties mainly due to increased crosslink density associated with the presence of natural accelerators and nano-scale dispersion obtained under acid free environment. The AFCC method is proposed as a new route in filler incorporation, which shows the best mechanical properties at a MMT loading of $8 \mathrm{phr}$. At higher MMT loadings, due to the formation of aggregated clay structures associated with filler-filler interactions, tensile strength and elongation at break decreased. Modulus and hardness increased with the increase of MMT loading, while tear strength remained unchanged. XDR deffractograms and SEM images revealed that the AFCC rubber at optimum loading has partially exfoliated clay structures with fine phase morphology. DSC analysis revealed that no significant rubber-filler interactions are formed in the rubber vulcanisates.
\end{abstract}

Keywords: Field latex, nanoclay filled dry rubber compounds, nanoclay incorporation methods, sodium montmorillonite.

\section{INTRODUCTION}

Natural rubber (NR) is the second largest type of rubber consumed in the world (MREPC, 2016). NR based products have a high demand due to the remarkable properties of NR not present in other materials. Excellent mechanical properties are maintained by NR with the addition of fillers, vulcanising systems and other specialty chemicals.
Particulate fillers are often incorporated into rubber to enhance various desirable properties necessary for different applications, and to reduce cost. Since the start of the twentieth century, conventional fillers, specially layered silicates, have beenutilised as effective reinforcing agents in rubber formulations to produce conventional composites for a variety of applications (Blacklley, 1997a). However, the expected property enhancement was not achieved. Many research studies (Okada et al., 1990; Aranda \& Ruiz - Hitzky, 1992; Gilman et al., 1997; Jayaraj et al., 2015) have been carried out to disperse nano level fillers in rubber to produce nanocomposites. With the help of modern techniques, layered silicates as nanofillers are now incorporated into rubber with significant improvement in physical properties (Gu et al., 2009; Rezende et al., 2010). The advantage of using nanofillers is not limited to reinforcement of rubber. This also results in a number of other properties such as barrier properties, flammability resistance and compatibility. In comparison to conventional composites, nanocomposites are favoured because a small fraction of nano-filler could impart a significant improvement in composite properties. This gives the advantage of producing a lightweight composite with excellent properties at low cost. Load transfer from rubber to filler is more efficient due to its good interfacial adhesion developed through higher surface area (Thomas \& Stephen, 2010). It also impedes propagation of cracks and improves the strength and toughness of the nanocomposite.

In conventional composites, clay tactoids with layers are generally aggregated in non-intercalated face-to-face form, resulting in poor mechanical properties (SanchezValdes et al., 2009). In nanocomposites, intercalated rubber-clay structures, which are formed by infiltration

*Corresponding author (sudarshana79@gmail.com) 
of one or more molecular layers of clay into inter-gallery spaces and exfoliated rubber-clay structures have been observed (Okada et al., 1990). Exfoliation is particularly desirable for improvement in properties that are affected by the degree of dispersion and the resulting interfacial area between rubber and clay nano-layers. Obtaining and retaining of exfoliated structures without disturbing through conventional rubber processing is the challenge.

In dry rubber product manufacturing industry, nanoclay fillers are incorporated into dry rubber using conventional processing techniques such as mechanical mixing method or solution blending method (Galimberti, 2011). In mechanical mixing method, it is difficult to exfoliate the clay due to the high viscosity of rubber. In the solution blending method, where clay is mixed with the rubber solution followed by evaporation of the solvent, it is difficult to intercalate rubber chains into silicate layers in solution state due to handling problem. However, recent research studies (Wang et al., 2005; Wu et al., 2005) have been focused on the preparation of nanoclay filled rubber through latex co-coagulation method, which could be later processed using conventional dry rubber processing techniques. In the co-coagulation method, a nanoclay aqueous suspension is first incorporated into latex and then coagulated to produce dry rubber. The NRrectorite nanocomposite was prepared with NR latex and rectorite clay aqueous suspension using co-coagulation followed by mechanical mixing method (Wang et al., 2005). Incorporation of nano-scale rectorite into NR increased the tortuosity of diffusive path for a penetrant gas molecule formed, and thereby improved the gas barrier property of the nanocomposite. Further, the nanocomposite showed superior stress-strain properties due to the reinforcement and the hindrance of rectorite layers to tensile crystallisation of NR.

Structures of several rubber-clay nanocomposites prepared by co-coagulating rubber latex, including NR, styrene butadiene rubber (SBR), acrylonitrile butadiene rubber (NBR) and carboxylated acrylonitrile butadiene rubber (CNBR), with clay aqueous suspensions (rectorite and MMT), have been discussed previously (Wang et al., 2005; Wu etal., 2005). It was revealed that a slight decrease in $\mathrm{d}_{001}$ basal spacing of the nanocomposite was caused by replacement of the original $\mathrm{Na}^{+}$ions by $\mathrm{H}^{+}$cations in the inter-gallery spaces of clay. The nano-dispersed structure reported was formed by encapsulation of individual or aggregated clay layers by rubber molecules and is completely different to the well-known intercalated structure and exfoliated structure. This implies that the intercalated rubber-clay structure could not be formed during co-coagulating method. However, the partly exfoliated structure, which is formed by the separation of encapsulated clay into individual or aggregated clay layers of nanolevel thickness without intercalation of rubber molecules into inter-gallery spaces, could be obtained when nanocomposites produced by the cocoagulating method are further subjected to mechanical shear.

Further, it has been revealed that intercalated or partly exfoliated structures in rubber-clay nanocomposites could be obtained by mechanical mixing of nanoclay with rubber (Wu et al., 2005). During mechanical mixing, rubber molecules are first intercalated into inter-gallery spaces of clay and results in decrease of interaction between clay layers. The intercalated clay is then exfoliated under mechanical shear and results in partly exfoliated structures. However, these structures show lower inter-gallery spaces compared to those of structures formed during co-coagulation followed by mechanical mixing method.

The main advantage of using co-coagulation followed by mechanical mixing method in the preparation of rubber-clay nanocomposites depends not only on enthalpic pathways of mechanical mixing, but also on clay dispersion in latex aqueous medium through entropic pathways (Vaia et al., 1993). The chance for aggregation of clay and creation of unfavourable conditions for vulcanisation under acidic medium are the main drawbacks of co-coagulation method. However, better properties are exhibited when using the co-coagulation method prior to mechanical mixing method.

Acid free co-coagulation method, which provides a solution to the common drawback of the co-coagulation method, is still in the developing stage (Nakason et al., 2015). In this method, sodium montmorillonite (MMT) clay is incorporated into field latex and then dried until a rubber sheet is obtained. Solid content of the clay-latex colloidal dispersion increases with evaporation of water, while drying becomes unstable and forms a composite. Mechanical properties of nanocomposites prepared using acid free co-coagulation followed by mechanical mixing method are expected to improve. This is associated with the less disturbed exfoliated structure of the aqueous clay suspension found during acid free cocoagulation. Therefore, the present study is focused on the evaluation of mechanical properties of rubber-clay composites prepared using acid co-coagulation followed by mechanical mixing method, and the acid free cocoagulation followed by mechanical mixing method. This paper further discusses the property variations of composites against nanoclay loading. 


\section{METHODOLOGY}

\section{Materials}

Natural rubber field latex having a total solid content of 33 wt \% was supplied by the Hanwella Rubber (Pvt.) Ltd., Sri Lanka. Sulfur (Rub-O-Sulf) as the vulcanising agent, mercaptobenzothiazole sulphanamide (Murcure MBTS, Merchem) as the accelerator, zinc oxide (White seal; ACPL-P999) as the inorganic activator, stearic acid (Lubstric, Godrej Industries Ltd.) as the organic activator, and phenolic type antioxidant (Lowinox CPL, Chempoint) were used in this work as per the rubber formulation given in Table 1. All chemicals were of industrial grade and were obtained from the Samson Compounds (Pvt.) Ltd. MMT or Cloisite-116 clay having a cation exchange capacity of $80 \mathrm{meq} / 100 \mathrm{~g}$ and an interlayer distance of $1.25 \mathrm{~nm}$, which was supplied by Southern Clay Products, USA, was used in dry rubber compounds as the nano-filler at different loadings.

Table 1: Formulation of dry rubber compounds

\begin{tabular}{lc}
\hline Ingredient & Loading, phr \\
\hline Rubber & 100 \\
MMT & $0,2,5,8,12,20$ \\
Sulphur & 2 \\
ZnO & 5 \\
Stearic acid & 2 \\
MBTS & 2 \\
Antioxidant & 1 \\
\hline
\end{tabular}

\section{Preparation of aqueous suspension of MMT}

A 5 wt $\%$ aqueous suspension of MMT was prepared by dissolving MMT in deionised water at $50{ }^{\circ} \mathrm{C}$ for $1 \mathrm{~h}$ using a magnetic stirrer followed by dispersing in a laboratory scale attrition mill for 30 min operated at a speed of $600 \mathrm{rpm}$.

\section{Preparation of MMT-filled rubber}

MMT-filled rubber sheets having MMT loadings of 2, $5,8,12$ and $20 \mathrm{phr}$ were prepared by incorporating an aqueous suspension of MMT into NR field latex using two methods, namely, acid co-coagulation (ACC) method and acid free co-coagulation (AFCC) method. In both methods, an aqueous suspension of MMT was mixed with field latex for $3 \mathrm{~h}$ at a speed of $50 \mathrm{rpm}$ until a homogeneous latex-MMT mix was obtained. In ACC method, which is similar to the method of producing ribbed smoke sheet rubber from field latex (Rathnayake, 2003), the latex-MMT mix was co-coagulated with $1 \%$ formic acid. The coagulum was washed thoroughly with water to remove acid and then pressed, first in a smooth mill and then in a diamond mill. Milled rubber was dried for $3 \mathrm{ds}$ at $50{ }^{\circ} \mathrm{C}$ in a smoke house and the resultant rubber is termed ACC rubber. In acid free co-coagulation method, the latex-MMT mix was poured into aluminium pans to $2-3 \mathrm{~mm}$ height and was dried for $2 \mathrm{ds}$ at $50{ }^{\circ} \mathrm{C}$ in an air circulated oven. Dried rubber was milled to obtain an even thickness and was dried again for another day in the oven under the same drying conditions. The resultant rubber is termed AFCC rubber.

\section{Preparation of dry rubber compounds}

Dry rubber compounds having MMT loadings of 2, 5, 8, 12 and 20 phr were prepared according to the formulation given in Table 1. Dry rubber compounds without MMT were prepared as controls. ACC rubber or AFCC rubber were first mixed in a Brabender plasticorder for 5 mins at different speeds of two rotors $36 \mathrm{rpm}$ and $42 \mathrm{rpm}$, respectively with zinc oxide, stearic acid and the antioxidant. Vulcanising ingredients were then mixed in a two-roll mill for another 2 mins.

\section{Determination of cure characteristics}

Cure characteristics were obtained using an oscillating disc rheometer operated at a temperature of $140{ }^{\circ} \mathrm{C}$ as per the ASTM standard D 2048-95. Minimum torque, maximum torque and scorch time that represents the time for a rise by two units from the minimum torque (cure time that corresponds to $90 \%$ of cure ) were determined. The cure rate is expressed as follows in equation (1).

$$
\text { Cure Rate }=\frac{T_{t_{90}}-T_{t s_{2}}}{t_{90}-t_{s_{2}}}
$$

where, $T_{t_{90}}$ is the toque at $t_{90}$

$$
T_{t s_{2}} \text { is the toque at } t_{s_{2}}
$$

\section{Determination of mechanical properties}

Compression moulded vulcanisates from different MMTfilled rubber compounds were prepared according to ASTM standard D3182-85, using an electrically heated hydraulic press operated at a temperature of $140{ }^{\circ} \mathrm{C}$ under $15 \mathrm{MPa}$, for tensile test, tear test and hardness. Hardness of the rubber vulcanisates was determined using a dead load hardness tester, according to ISO 48:2010. 
Respective optimum cure times, $t_{90}$, were determined from rheographs. Tensile properties and tear strength of rubber vulcanisates were determined using a Hounsfield H10KT tensile tester as per ISO 37:2011 and ISO 34-1:2010, respectively. Dumbbell specimens and angle specimens were cut from $2 \mathrm{~mm}$ thick vulcanised sheets using a die cutter to determine the tensile properties and tear strength, respectively. Both tests were carried out at $28 \pm 2{ }^{\circ} \mathrm{C}$ under a strain rate of $500 \mathrm{~mm} / \mathrm{min}$. Extension was taken as the movement of crosshead.

\section{Determination of crosslink density}

Test specimens having dimensions of $15 \times 15 \times 2 \mathrm{~mm}$ of both unfilled and filled rubber vulcanisates were swollen in toluene for $48 \mathrm{~h}$ in a dark environment and dried in a vacuum oven at $60{ }^{\circ} \mathrm{C}$ until a constant weight was achieved. The weight measurement of a specimen; before swelling, swollen gel and after drying were recorded and used to determine the crosslink density. Volume fraction $(v)$ is the crosslink density by moles per cubic centimeter and is given by equation (2).

$v=1 / 2 M_{c}$

where $M_{c}$ is the molar mass between the crosslink of rubber vulcanisate and it is calculated by the Flory Rehner equation (Flory \& Rehner, 1943; Khinnavar \& Aminabhavi, 1991).

$M_{C}=\frac{-\rho_{r} \times V_{s} \times V_{r}^{1 / 3}}{\ln \left(1-V_{r}\right)+\left(V_{r}+\varkappa V_{r}^{2}\right)}$

where,

$\rho_{r}$ - density of NR $\left(0.92 \mathrm{gcm}^{-3}\right)$

$V_{S}$ - molar volume of toluene $\left(106.35 \mathrm{~cm}^{3} \mathrm{~mol}^{-1}\right)$

$x$ - Flory-Hugging polymer-solvent interaction (0.39) for NR-toluene

$V_{r}$ - volume of fraction of rubber in swollen gel

$V_{r}$ is calculated using Ellis and Welding (Ellis \& Welding, 1964; Cassidy et al., 1983) as given in equation (4).

$V_{r}=\frac{(D-F W) \rho_{r}}{\frac{(D-F W)}{\rho_{r}}+\frac{A_{o}}{\rho_{s}}}$

where,

$A_{o}$ - weight of absorbed solvent

$\rho_{s}$ - density of solvent $(0.87)$

$D$ - de-swollen weight
F - weight fraction of the filler

W - initial weight of the sample

\section{$\mathrm{X}$-ray diffraction analysis}

$\mathrm{X}$-ray diffraction (XRD) technique was used to evaluate the intercalation or exfoliation behaviour of MMT clay in NR. XRD analysis of the ACC rubber and AFCC rubber was performed using a Bruker D8 diffractometer at a wavelength of $1.54 \AA$ of $\mathrm{Cu} \mathrm{K} \alpha$ radiation. Scanning was carried out over a Bragg angle $(2 \theta)$ ranging from $3-10^{\circ}$ at a rate of $0.02^{\circ} / \mathrm{sec}$. Inter-gallery spacing of MMT in NR was calculated using the conventional Bragg equation, which is given below.

$n \lambda=2 d \sin \theta$

where,

$\lambda$ - wave length of X-rays

$d$ - crystal lattice spacing

$\theta$ - angle between incident radiation and scattering plan

$n$ - order of diffraction

\section{Morphology}

The morphology of clay and its dispersion within the NR composites was observed under the scanning electron microscope (SEM) Carl Zeiss EVOLS, at an acceleration voltage of $15 \mathrm{kV}$. Cross sections of the composites were gold coated before observing under the SEM.

\section{Determination of glass transition temperature}

Glass transition temperature was determined using a differential scanning calorimeter (DSC) from TA instruments, USA according to ISO 22768: 2006. A sample of $7 \mathrm{mg}$ from each composite was placed in a tzero pan and the test was run at a heating rate of $3{ }^{\circ} \mathrm{C} / \mathrm{min}$ over a temperature range of -75 to $-55{ }^{\circ} \mathrm{C}$ in nitrogen environment maintained at a flow rate of $35 \mathrm{~mL} / \mathrm{min}$.

\section{Analysis of metal ions}

The content of copper $(\mathrm{Cu})$, magnesium $(\mathrm{Mg})$, iron $(\mathrm{Fe})$ and manganese $(\mathrm{Mn})$ in selected filled and unfilled rubber compounds was analysed using an absorption spectrometric method. About $5 \mathrm{~g}$ of the homogenised sample was accurately weighted and burnt in a muffle furnace at $550{ }^{\circ} \mathrm{C}$. The ashes were digested by concentrated hydrochloric acid and were filtered before analysing using an atomic absorption spectrophotometer (Model GBC Avanta M). 


\section{RESULTS AND DISCUSSION}

\section{Comparison of AFCC and ACC methods}

The cure characteristics of rubber compounds at different MMT loadings have been shown in Table 2. Cure time $\left(t_{90}\right)$ of the AFCC rubber compound is approximately four times lower than that of the ACC rubber compound at the same MMT loading. Further, the scorch time $\left(t_{\mathrm{c}_{2}}\right)$ of AFCC rubber compound is lower than that of the ACC rubber compound, while cure rate of the AFCC rubber compound is greater than that of the ACC rubber compound at every MMT loading. In AFCC method, natural subtances like proteins and phospholipids are remained in the dry rubber as only water from the latex medium is evoporated. In ACC method, water and natural subtances are removed at the stage of sheeting and milling. Natural subatances play a significant role in reducing the cure time by acting as accelerators (Zhong et al., 2009). Therefore, the presenece of natural substances in AFCC rubber accelarates the vulcanisation process. The presence of formic acid in ACC rubber, which is used to destabilise rubber at latex stage, slows down the reaction of zinc oxide with stearic acid to produce zinc soap complexes during the initial step of vulcanisation, and instead forms zinc formate. The low levels of zinc soap complexes produced hinder the initiation of vulcanisation process and thereby increase the scroch time. The increase of scorch time and the decrease of cure rate for ACC rubber compounds lengthen the resultant cure times compared to those for AFCC rubber compounds.

Table 2: Cure characteristics of AFCC and ACC rubber vulcanisates at different MMT loadings

\begin{tabular}{lllcc}
\hline & $\mathrm{t}_{\mathrm{S} 2}, \min$ & $\mathrm{t}_{90}, \min$ & $\mathrm{M}_{\mathrm{H}}-\mathrm{M}_{\mathrm{L}}, \mathrm{dN}$ & $\begin{array}{c}\text { Cure rate, } \\
\mathrm{dN} / \mathrm{min}\end{array}$ \\
\hline AFCC 0 & 2.0 & 11.2 & 167.5 & 4.0 \\
AFCC 2 & 2.9 & 12.5 & 144.9 & 13.1 \\
AFCC 5 & 3.2 & 12.3 & 187.5 & 18.4 \\
AFCC 8 & 2.2 & 11.0 & 197.7 & 19.8 \\
AFCC 12 & 2.5 & 12.1 & 183.1 & 15.1 \\
AFCC 20 & 3.2 & 13.8 & 170.6 & 16.6 \\
ACC 0 & 12.7 & 41.6 & 163.6 & 5.03 \\
ACC 2 & 10.3 & 49.7 & 154.5 & 3.5 \\
ACC 5 & 8.8 & 44.8 & 151.3 & 3.7 \\
ACC 8 & 7.8 & 41.2 & 181.8 & 4.8 \\
ACC 12 & 8.0 & 36.1 & 180.5 & 5.6 \\
ACC 20 & 7.6 & 36.3 & 169.4 & 5.1 \\
\hline
\end{tabular}

Crosslink densities for AFCC rubber and ACC rubber vulcanisates at different MMT loadings are shown in Figure 1. The crosslink density for AFCC rubber vulcanisates show higher values than those for ACC rubber vulcanisates at every MMT loading. The absence of natural substances as accelerators and the acid environment in ACC rubber compounds retard the formation of crosslinks between rubber molecules and thereby exhibit lower crosslink densities. The higher level of MMT aggregation in ACC rubber under acidic environment may also adversely influence the crosslink density. Therefore, crosslink densities of ACC rubber vulcanisates are lower than those of AFCC rubber vulcanisates (Figure 1). It was found in literature (Amarasiri et al., 2013) that clay in exfoliated structures compared to intercalated structures has an effect to enhance the crosslink density.

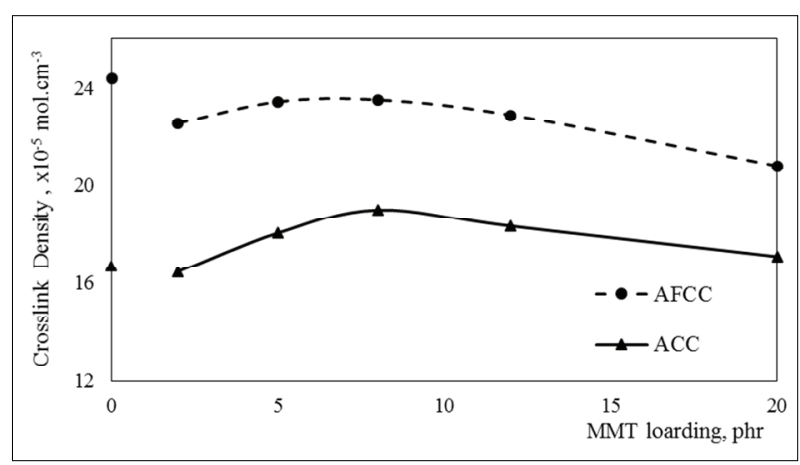

Figure 1: Crosslink densities of rubber vulcanisates at different MMT loadings

Clay layers in MMT are homogeneously dispersed in rubber latex by mechanical mixing and the rubber particles penetrate through clay layers and stabilise the clay-rubber dispersion, preventing aggregation of rubber particles if disordered partially exfoliated structures and interlaced clay structures are formed. It was reported $(\mathrm{Wu}$ et al., 2005) that $2 \theta$ shifted to lower side and the inter gallery spaces $\left(\mathrm{d}_{001}\right)$ increased when partially exfoliated clay structures are formed in rubber composites, and it may be due to the function of MMT as steric stabiliser. XRD difractrogram for pure MMT is given in Figure 2 (b), while those for AFCC rubber compound and ACC rubber compound at different MMT loadings are given in Figure 2 (a). ACC rubber at 8 phr loading shows a peak having $\mathrm{d}_{001}$ of $2.2 \mathrm{~nm}$, while AFCC rubber at $8 \mathrm{phr}$ loading does not exhibit a significant peak. This implies that AFCC rubber contains more exfoliated structures than intercalated structures, which exhibits inter gallery 
spaces in XRD diffractograms. It was observed during the study that the latex was stabilised with the addition of MMT, and the stabilised latex prevented co-coagulation under the recommended acid level practicing in ribbed smoke sheet rubber manufacturing process (Ratnayake, 2003). Therefore, increased acid levels were added to the co-coagulate latex in producing ACC rubber. ACC rubber at other loadings shows highly variable $d_{001}$ values with different intensities. This may be due to the poor degree of dispersion of MMT in rubber matrix associated with highly aggregated MMT stacks formed in the presence of acid. During ACC rubber manufacturing process, clay aggregates with different levels of intercalated structures, instead of the expected exfoliated structure, may be formed. This is confirmed by scanning electron microscopic (SEM) images of AFCC rubber and ACC rubber having a MMT loading of $8 \mathrm{phr}$, which are shown in Figure 3. The SEM image for AFCC rubber (Figure 3b) shows homogeneously distributed and finely dispersed clay stacks, while that for ACC rubber (Figure 3a) shows the aggregation of clay stacks rather than fine morphology. AFCC rubber compared to ACC rubber shows less aggregation of clay stacks and better distribution.

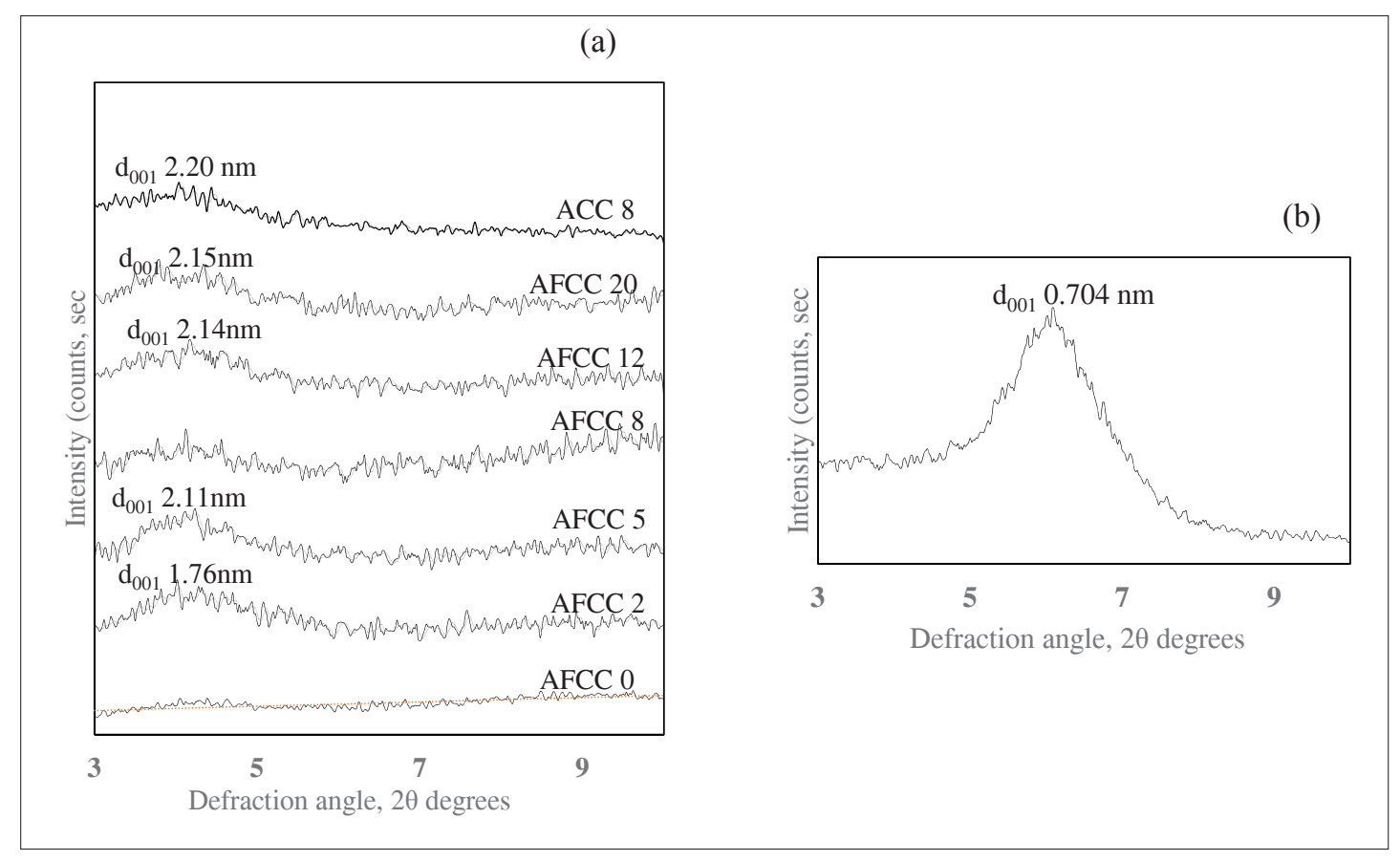

Figure 2: XRD diffractograms of (a) AFCC rubber and ACC rubber at different MMT loadings; (b) pure MMT
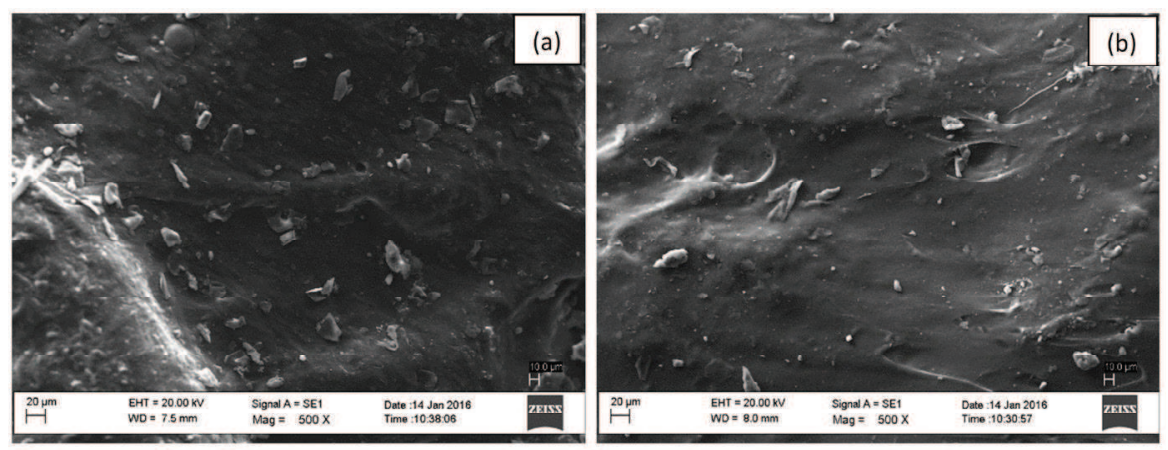

Figure 3: SEM images of (a) ACC rubber; (b) AFCC rubber 


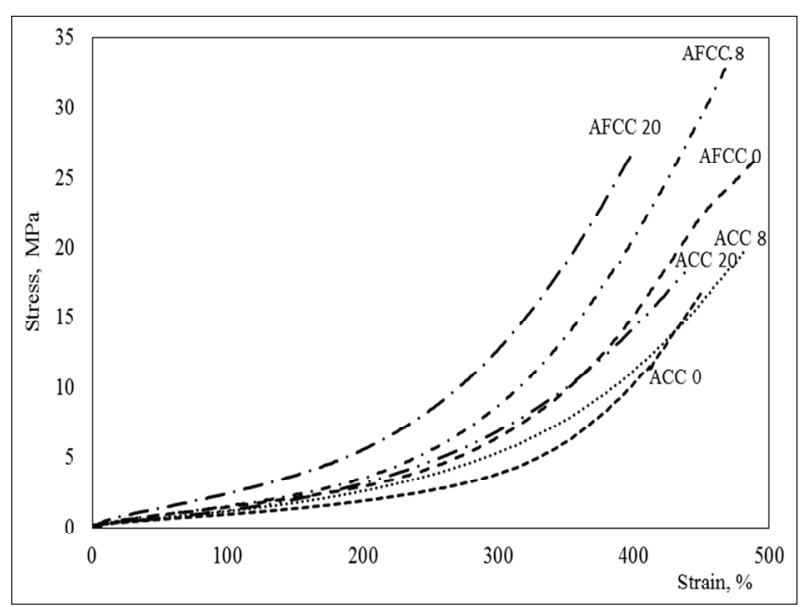

Figure 4: Stress-strain curves of AFCC rubber and ACC rubber at different MMT loadings

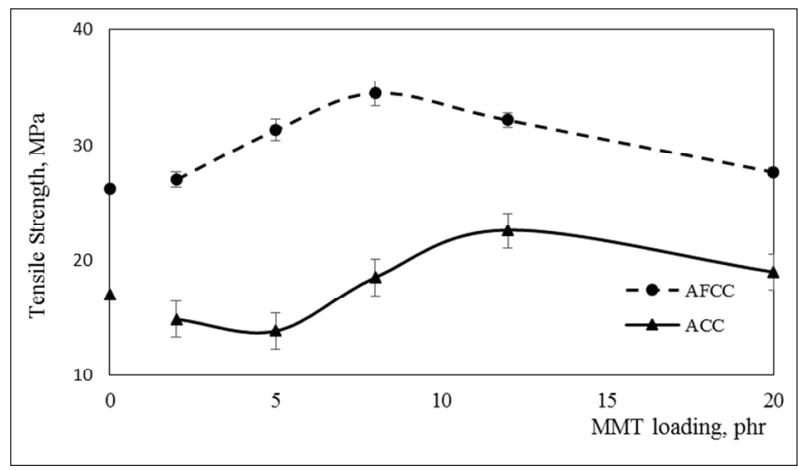

Figure 5: Tensile strength of rubber vulcanisates at different MMT loadings

Stress-strain curves for AFCC rubber vulcanisates and ACC rubber vulcanisates at different MMT loadings are given in Figure 4. Variations of tensile strength, elongation at break and modulus at $300 \%$ elongation against MMT loadings for both rubbers are shown in Figures 5, 6 and 7, respectively. The maximum tensile strength for AFCC rubber vulcanisate is recorded at $8 \mathrm{phr}$ loading, while that for ACC rubber vulcanisates is at $12 \mathrm{phr}$ loading. Elongations at breaks and moduli for AFCC rubber vulcanisates are higher than that for ACC rubber vulcanisates. Maximum elongations at breaks are shown at $8 \mathrm{phr}$ loading.

Tensile strength, elongation at break and modulus at $300 \%$ elongation for AFCC and ACC rubber vulcanisates extended over a range of $15-35 \mathrm{MPa}, 400-500 \%$ and 4 - $9 \mathrm{MPa}$, respectively. Both $\mathrm{AFCC}$ and $\mathrm{ACC}$ rubber vulcanisates exhibited a strain induced crystallisation nature during tensile straining (Figure 4), and further the effect was enhanced with AFCC rubber vulcanisates. Hence, compared to ACC rubber vulcanisates, AFCC rubber vulcanisates with and without MMT exhibited enhanced tensile properties. Further, AFCC rubber vulcanisates show approximately $50 \%$ increase of tensile strength compared to ACC rubber vulcanisates. This property enhancement is associated with the increased crosslink densities of AFCC rubber vulcanisates (Figure 1) and their fine morphology (Figure 3). It was also reported (Blacklley, 1997b; Gonzalez et al., 2005) that the natural proteins and phospholipids in natural rubber affect the degree and the chemical nature of crosslinks and have the ability to promote crystallisation, and thereby improve the mechanical properties of their vulcanisates. Further, the nano-scale dispersion of MMT layers in rubber provides an efficient reinforcement without aggregation, and leads to improved stiffness due to the formation of immobilised or partially immobilised rubber (Kojima et al., 1993). The nano-structures will distribute stress evenly through the rubber, resulting a minimum crack growth even at higher elongation at

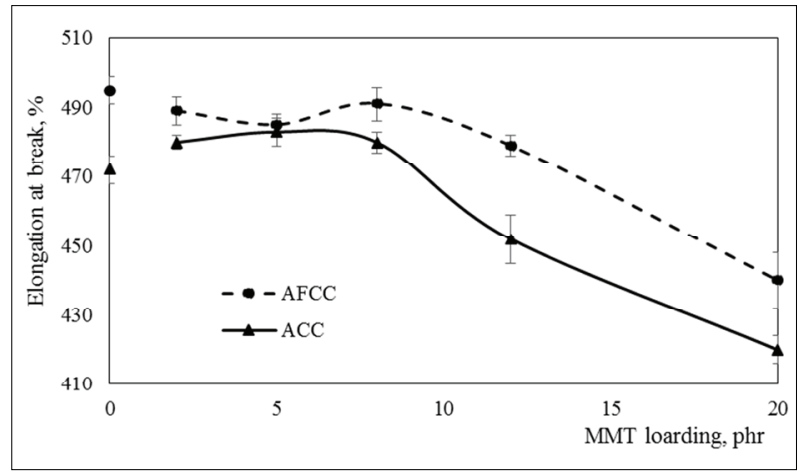

Figure 6: Elongation at break of rubber vulcanisates at different MMT loadings

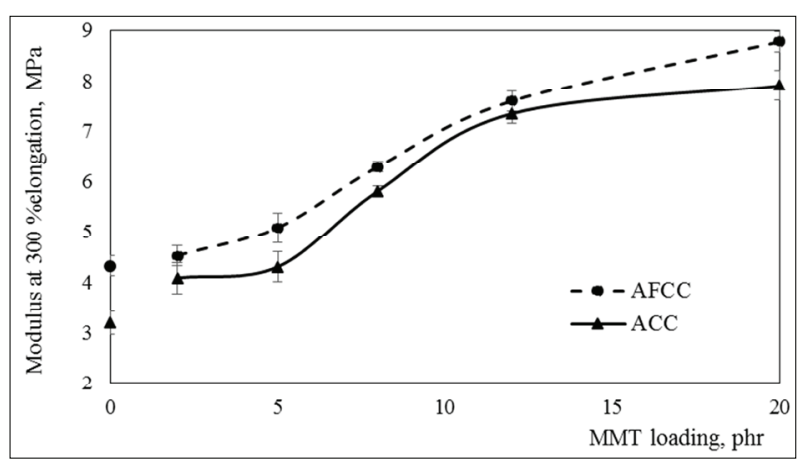

Figure 7: Modulus at $300 \%$ elongation of rubber vulcanisates at different MMT loadings 
break, leading to higher tensile stress before fracture. On the other hand, clay aggregation in acidic environment in ACC rubber deteriorates tensile properties due to minimising effective surface area of clay particles. The aggregated clay stacks encapsulated by rubber will be difficult to exfoliate. Accordingly, the ACC rubber vulcanisates failed at low stresses resulting in relatively low tensile properties, due to poor distribution of stresses under highly aggregated MMT structures formed under acid envoironment. However, the tensile properties of rubber vulcanisates prepared by the co-coagulation method were better than those prepared by mechanical mixing (Wu et al., 2005; Gu et al., 2009). These results suggest the necessity of a new methodology as an alternative to prevent the aggregation of MMT as much as possible to improve the properties expected from nano behaviour.

The hardness of AFCC and ACC rubber vulcanisates at different MMT loadings are shown in Figure 8. Both rubber vulcanisates show maximum hardness at $8 \mathrm{phr}$ loading. It is well known that the hardness of rubber vulcanisate is difficult to improve using MMT unlike

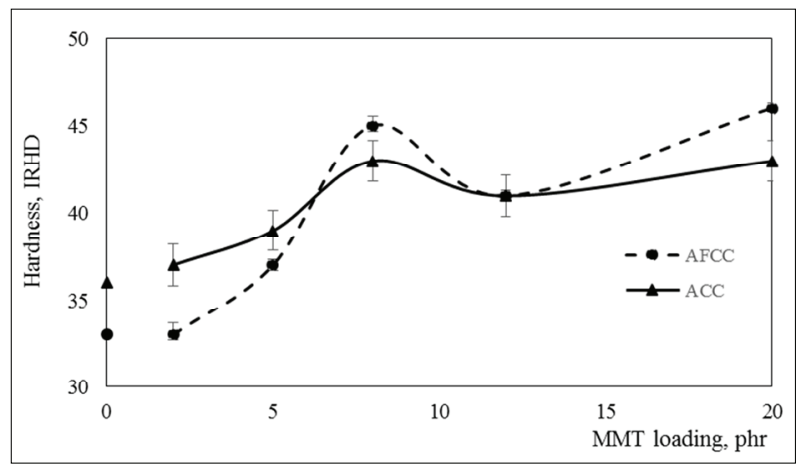

Figure 8: Hardness of rubber vulcanisates at different MMT loadings

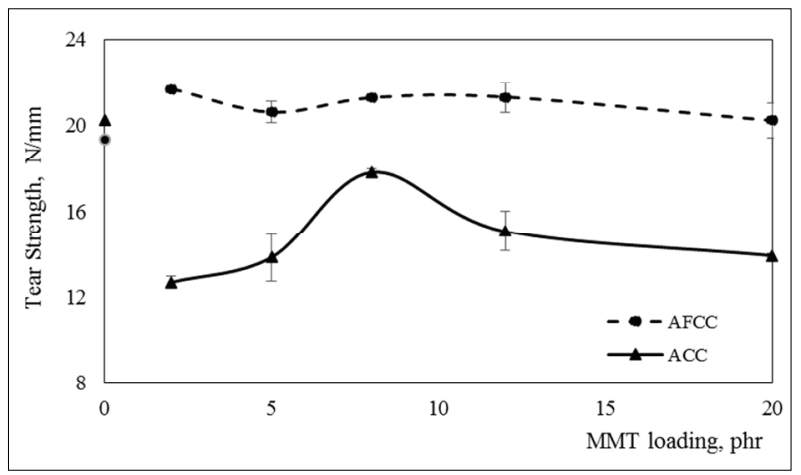

Figure 9: Tear strength of rubber vulcanisates at different MMT loadings carbon black, by mechanical mixing or co-coagulation method (Rattanasom et al., 2009). However, the hardness of rubber vulcanisates may vary with crosslink density and morphology.

Tear strengths of the AFCC and ACC rubber vulcanisates at different MMT loadings are shown in Figure 9. AFCC rubber vulcanisates show higher tear strengths at every MMT loading compared to ACC rubber vulcanisates. In general, a poor tear strength of MMT filled rubber composite was observed if the clay platelets were aligned in the perpendicular direction to the applied force, as stress might be concentrated at the sharp edges of particles and promote early failure compared to spherical fillers (Rattanasom et al., 2009). In this study, AFCC rubber vulcanisates exhibited greater tear strengths compared to those of ACC rubber vulcanisates. This variation might be due to the fine morphology of the AFCC rubber. The enhanced properties of AFCC rubber suggest that the AFCC method is better than the ACC method.

In the AFCC rubber manufacturing process, only water is evaporated, accumulating metal ions in rubber. $\mathrm{Cu}$ ion and $\mathrm{Mn}$ ion content of the AFCC rubber were 2.7 and $1.2 \mathrm{ppm}$, while those of the ACC rubber were 7.6 and $0.7 \mathrm{ppm}$, respectively. As per the ISO 6101-3:2014 and ISO 6101-4: 2014 (2014a; b) the effect of $\mathrm{Cu}$ and $\mathrm{Mn}$ ions on the ageing properties are not significant if the concentrations are below $8 \mathrm{ppm}$. $\mathrm{Mg}$ ion and Fe ion content in AFCC rubber were 481 and $21 \mathrm{ppm}$, while those for ACC rubber were 239 and 1323 ppm, respectively. The Mg ion content in both rubbers is in the accepted range similar to the $\mathrm{Mg}$ ion content of ribbed smoked sheet. The high Fe ion content in ACC rubber may be due to contamination during manufacturing (Ratnayake et al., 2011). The effect of Mg ions on ageing of rubber is not much significant compared to the effect of $\mathrm{Cu}, \mathrm{Mn}$ and $\mathrm{Fe}$ ions. It was shown that these three ions decreased the activation energy of NR and thereby accelerated the thermo-oxidative degradation of rubber vulcanisates (Goh \& Phang, 1978).

\section{Effect of MMT loading}

Mechanical and chemical properties also depend on the MMT loading and is mainly associated with the degree of MMT dispersion and the structure of MMT in rubber composites. Cure times of ACC rubber compounds decrease with the increase in MMT loading (Table 2). Higher MMT loadings use more acid to form MMT stacks depending on the cation exchange capacity of MMT, and hence a small level of acid is available to form zinc formates, which delays the first step of the 
vulcanisation process. No such variation of cure times was observed with AFCC rubber compounds due to its acid free environment. However, the $M_{H}-M_{L}$ value, which gives a direct relationship to the crosslink density increases with MMT loading and decreases after that, passing through an optimum MMT loading at $8 \mathrm{phr}$. The lowest scorch time, the highest cure rate and thereby the lowest cure time were obtained at a MMT loading of 8 phr. This may be due to exfoliated clay strcutures formed in AFCC rubber compounds at $8 \mathrm{phr}$ MMT loading. It was reported (Sun et al., 2008; Rooj et al., 2012) that various accelerators, especially ammine groups and organo cations etc., dispersed well in exfoliated structures would increase the cure rate. Similarly, higher levels of natural proteins and phospholipids in AFCC would disperse effectively in exfoliated structures at MMT loading of 8 phr and increase the cure rate.

The addition of MMT either to AFCC or ACC rubber at lower loadings provides nano-dispersed reinforcement due to its high surface area and formation of physical crosslinks in the rubber chain acting as physical crosslinking junctions. However, a higher loading of MMT in rubber forms aggregated clay stacks and increases the size of the dispersed phase and reduces the surface area. Correspondingly, the stress transition caused by tensile crystallisation gradually weakens and even disappears, and a hindrance of reinforcement is resulted. The aggregated polar MMT structures in non-polar rubber act as incompatible particle fillers that may scavenge rubber radicals and hinder the radical-radical interactions and hence, reduce the formation of rubber crosslink network (Sharif et al., 2005). Further, the aggregated sites may act as fracture initiation points and may result in a failure under the effect of external load (Moczo \& Punanszky, 2008). Crack propagation is limited when higher degrees of exfoliation are achieved. Therefore, higher stresses are required to fracture a composite with nanostructures. As a result, the tensile strength increases up to $35 \mathrm{MPa}$ up to a MMT loading of $8 \mathrm{phr}$ in AFCC rubber vulcanisates and decreases thereafter. A similar variation was exhibited by ACC rubber vulcanisates with an optimum at a MMT loading of $12 \mathrm{phr}$. Elongation at break for both rubber vulcanisates decreased after a MMT loading of $8 \mathrm{phr}$. It has been identified in previous studies (Wang et al., 2005; Wu et al., 2005) that the addition of MMT would give stiffness to natural rubber, thus resulting in a reduction of elongation at break after a certain loading of MMT.

Modulus at $300 \%$ elongation of rubber vulcanisates exhibited an increase in the trend at lower MMT loadings due to nano-scale dispersion of MMT in rubber. The modulus further increased with the increase in MMT loading since the aggregated MMT particles behave as conventional filler. Hardness increased from 32 to 45 IRHD (international rubber hardness degree) with the increase in MMT loading. A remarkable sudden increase in hardness was exhibited at a MMT loading of $8 \mathrm{phr}$ for both rubber vulcanisates, although the modulus exhibited a gradual increase in the trend with MMT loading. These results propose that the MMT loading of $8 \mathrm{phr}$ might behave as nano-dimensional filler in AFCC rubber due to the formation of exfoliated clay structures. Conventional fillers in general provide an increase in hardness and modulus together with the increase in filler loading (Blacklley, 1997a).

DSC thermograms for AFCC rubber and ACC rubber at different MMT loadings are shown in Figure 10. Glass transition temperature for both rubbers at every MMT loading exhibited the same value and is around $-63{ }^{\circ} \mathrm{C}$. This implies that strong rubber-filler interactions are not developed in the composites for enhancement of mechanical properties of the vulcanisates in the present study. This confirms that the greater property enhancement at MMT loading of $8 \mathrm{phr}$ is mainly due to the formation of more exfoliated clay structures than intercalated clay structures in AFCC rubber and the increased crosslink density.

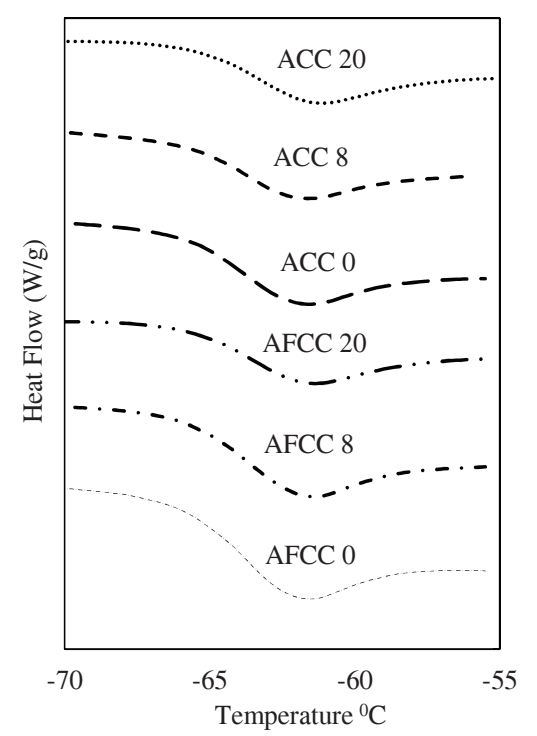

Figure 10: DSC thermogram of AFCC rubber and ACC rubber at different MMT loadings

Voids found in the exfoliated structures influence physical crosslinks although rubber-filler interactions are not developed. The occluded rubber, unlike bound rubber, effectively distributes in stable exfoliated structure and 
impedes crack propagation while promoting mechanical properties in AFCC rubber vulcanisates. The effective dispersed layered silica allows the creation of voids in rubber network and resists crack propagation, and withstand against high stresses without breaking (Gatos et al., 2004; Rattanasom et al., 2009). Shortening the stack-to-stack distance can lead to greater resistance to crack propagation. Furthermore, the increased length of the zig-zag cracks path support for energy dissipation. More or less similar tear strength at every MMT loading for AFCC rubber vulcanisates suggest the formation of voids at certain extent in every AFCC rubber vulcanisate.

Pure MMT shows a peak at a diffraction angle of $6^{\circ}$ (Figure 2b). With the incorporation of MMT into rubber, the diffraction angle moves to the lower side, approximately at $4^{\circ}$. Further, XRD diffractograms showed that the intensity of peak and the inter gallery space $d_{001}$ varies with the MMT loading. The highest $d_{001}$, which is associated with the lower peak intensity was recorded at a MMT loading of $8 \mathrm{phr}$ for ACC rubber. It might be due to the balance of repulsion between MMT and rubber, homogeneously dispersed at the effective MMT loading. However, decrease in the intensity of peak may also be due to the low concentration of MMT. Disappearance of the corresponding peak in AFCC rubber at a MMT loading of $8 \mathrm{phr}$ confirms that more exfoliated clay structures are presented in the rubber composite.

Although improved mechanical properties were obtained with AFCC rubber at a MMT loading of $8 \mathrm{phr}$, the expected enhancement in tensile properties was not found. This may be due to poor rubber-filler interactions. Further the MMT loading, which exhibited optimum properties is high. Therefore, future studies are focused to modify MMT and/or rubber in order to obtain improved rubber-filler interactions rather than filler-filler interactions and thereby to obtain improved properties at lower MMT loadings, especially in dry rubber compounding when this new AFCC method is introduced.

$\mathrm{Cu}, \mathrm{Mn}, \mathrm{Fe}$ and $\mathrm{Mg}$ ions in $\mathrm{AFCC}$ rubber containing $12 \mathrm{phr}$ of MMT loading, which is the highest loading studied, were 3.8, 2.7, 958 and 4263 ppm, respectively. This shows that the effect of $\mathrm{Cu}$ and $\mathrm{Mn}$ ions on ageing properties is not significant even at higher MMT loadings. It was reported (Uddin, 2008) that MMT contains a significant amount of $\mathrm{Mg}$ and $\mathrm{Fe}$ ions and those ions may also be responsible to increase the ion content in rubber. However, the remarkable ageing resistant of MMT may reduce such adverse effects (Jurkowska et al., 2007; Park et al., 2012).

\section{CONCLUSION}

AFCC rubber contained higher levels of natural substances like proteins and phospholipids, which act as accelerators during vulcanisation, and hence the crosslink density is increased while reducing the cure time. This higher crosslink density and the fine morphology of the dispersed MMT phase provide better mechanical properties. ACC rubber did not contain higher levels of natural substances as they are removed during processing and thereby the crosslink density of the ACC rubber vulcanisates is lowered, while increasing the cure time. These effects are further enhanced with the formation of aggregated clay stacks in ACC rubber in the presence of acids, and relatively lower mechanical properties were resulted. Therefore, the AFCC method can be considered as the best method to prepare MMT filled natural rubber composites.

Tensile strength increased with the addition of MMT at lower loadings up to $8 \mathrm{phr}$ due to strain-induced crystallisation promoted by nano-scale dispersion, and decreased thereafter. Modulus and hardness increased with the MMT loading, while elongation at break decreased after a $8 \mathrm{phr}$ MMT loading. However, hardness was highest at a MMT loading of $8 \mathrm{phr}$. The enhanced properties of the rubber vulcanisates at $8 \mathrm{phr}$ MMT loading is associated with the exfoliated structures formed as evidenced by the XRD diffractogram and SEM image. At higher MMT loadings, aggregated clay structures are formed due to prominent filler-filler interactions. The absence of rubber-filler interactions in the composites was proven by obtaining a constant glass transition temperature for AFCC rubbers at all MMT loadings. However, due to the presence of a considerable amount of voids in the rubber network in AFCC rubber vulcanisates, tear strength did not vary with the MMT loading.

The optimum loading to prepare nanoclay filled dry natural rubber compounds using AFCC method was found as $8 \mathrm{phr}$. This loading is significantly high to facilitate full exfoliation of MMT, and hence future studies are focused on modifications of MMT and/or rubber to obtain enhanced properties at lower MMT loadings.

\section{Acknowledgement}

This research project was supported by the University of Moratuwa Senate Research Grant Number SRC/ $\mathrm{CAP} / 14 / 05$. 


\section{REFERENCES}

1. Aranda P. \& Ruiz-Hitzky E. (1992). Poly(ethylene oxide)silicate intercalation materials. Chemistry of Material 4(6): 1395 - 1403.

2. Amarasiri A., Ratnayake U.N., Silva U.K., Walpalage S. \& Siriwardena S. (2013). Natural rubber latex-clay nanocomposite: use of montmorillonite clay as an alternative for conventional $\mathrm{CaCO}_{3}$. Journal of the National Science Foundation of Sri Lanka 41(4): 293 - 302.

DOI: http//dx.doi.org/doi.10.4038/jnsfsr.v41i4.6258

3. Blacklley D.C. (1997a). Application of latices. Polymer Latices Science and Technology, volume 3, $2^{\text {nd }}$ edition, pp. 79 - 81. Chapman and Hall, London, UK.

4. Blacklley D.C. (1997b). Types of latices. Polymer Latices Science and Technology, volume 2, 2nd edition, pp. $93-97$. Chapman and Hall, London, UK.

5. Cassidy P.E., Aminabhavi T.M. \& Thompson C.M. (1983). Water permeation through elastomers and plastics. Rubber Chemistry and Technology 56(3): $594-618$.

DOI: http://dx.doi.org/10.5254/1.3538143

6. Ellis B. \& Welding G.N. (1964). Estimation from swelling of the structural contribution of chemical reactions to the vulcanization of natural rubber II. estimation of equlibrium degree of swelling. Rubber Chemistry and Technology 37(2): $571-575$.

DOI: http://dx.doi.org/10.5254/1.3540349

7. Flory P.J. \& Rehner J.R. (1943). Statistical mechanics of cross-linked polymer networks II. swelling. Journal of Chemical Physics 11(11): 521 - 526.

8. Galimberti M. (2011). Rubber-clay Nanocomposites; Science, Technology, and Applications. John Wiley and Sons Inc., New York, USA.

DOI: https://doi.org/10.1002/9781118092866

9. Gatos K.G., Sawanis N.S., Aponstoloy A.A., Thomann R. \& Karger-kocsis J. (2004). Nanocomposite formation in hydrogenated nitrile rubber (HNBR)/ organo-montmorillonite as a function of the intercalant. Macromolecular Materials and Engineering 289(12): 1079 -1086 .

DOI: https://doi.org/10.1002/mame.200400214

10. Gilman J.W., Kashiwagi T. \& Lichtenhan J.D. (1997). Flammability studies of polymer-layered silicate nanocomposites. SAMPE Journal 33(40): $40-45$.

11. Goh S.H. \& Phang K.W. (1978). Thermoanalytical studies of rubber oxidation catalysed by metallic ions. Thermochemica Acta 25(1): 109.

12. Gonzalez L., Rodriguez A. \& Valentin J.L. (2005). Conventional and efficient crosslinking of natural rubber: effect of heterogeneities on the physical properties. $K G K$ Rubber Point 58(12): $638-643$.

13. Gu Z., Song G., Liu P., Gao P., Li H. \& Hu X. (2009). Preparation and properties of styrene butadiene rubber/ natural rubber/ organo-bentonite nanocomposites prepared from latex dispersions. Applied Clay Science 46(3): $241-$ 244.

DOI: https://doi.org/10.1016/j.clay.2009.08.010
14. International Organization for Standardization (2014a). ISO 6101-3:2014. Rubber - Determination of Metals Content by Atomic Absorption Spectrometry - Part 3: Determination of Copper Content. International Organization for Standardization, Geneva, Switzerland.

15. International Organization for Standardization (2014b). ISO 6101-4:2014. Rubber - Determination of Metals Content by Atomic Absorption Spectrometry - Part 4: Determination of Manganese Content. International Organization for Standardization, Geneva, Switzerland.

16. Jayaraj S., Egodage S.M. \& Walpalage S. (2015). Review on development of natural rubber/ nanoclay nanocomposites. Proceedings of the Moratuwa Engineering Research Conference (MERCon, 2015), University of Moratuwa, Moratuwa, Sri Lanka, 7 - 8 April, pp. 18 - 23.

DOI: https://doi.org/10.1109/MERCon.2015.7112313

17. Jurkowska B., Jurkowski B., Oczkowski M., Pesetskii S.S., Koval V. \& Oikhov Y.A. (2007). Properties of montmorillonite-containing natural rubber. Journal of Applied Polymer Science 106(1): 360 - 371.

DOI: https://doi.org/10.1002/app.26657

18. Khinnavar R.S. \& Aminabhavi T.M. (1991). Diffusion and sorption of organic liquids through polymer membranes I. polyurethane verses n-alkanes. Journal of Applied Polymer Science 42(8): 2321 - 2328.

DOI: https://doi.org/10.1002/app.1991.070420823

19. Kojima Y., Usuki A., Kawasumi M., Okada A., Kurauchi T. \& Kamigaito O. (1993). Sorption of water in nylon 6-clay hybrid. Journal of Applied Polymer Science 49(7): 1259 1264.

DOI: https://doi.org/10.1002/app.1993.070490715

20. Malaysian Rubber Export Promotion Council (MREPC) (2016). World Production, Consumption and Trade of Rubber. Malaysian Rubber Export Promotion Council, Kuala Lumpur, Malaysia, Available at http://www.mrepc. com, Accessed 23 April 2016.

21. Moczo J. \& Punanszky B. (2008). Polymer micro and nanocomposites: structure, interactions, properties. Journal of Industrial and Engineering Chemistry 14(5): 535 - 563. DOI: http//dx.doi.org/doi:10.1016.j.jiec.2008.06.011

22. Nakason C., Sookyung U., Vennemann N. \& Thaijaroen W. (2015). Acid-free Preparation of Natural Rubber/Clay Nanocomposite. Society of Plastic Engineering. Available at http://www.4spepro.org, Accessed 23 April 2016.

DOI: http//dx.doi.org/doi.10.2417/spepro.005901

23. Okada A., Kawasami M., Usuki A., Kajima Y., Kurauchi T. \& Kamigaito O. (1990). Synthesis and properties of nylon-6/clay hybrids. Polymer based molecular composites. MRS Symposium Proceedings (eds. D.W. Schaefer \& J.E. Mark), Pittsburgh, USA 171: 45 - 50.

24. Park J., Lee C.W., Yang Y., Lee J., Nam G., Lee S., Lee Y.S., Lee Y. \& Nam D. (2012) Montmorillonitereinforced natural rubber nanoomposites through emulsion stabilization destabilization method. Rubber Chemistry and Technology 85(2): 165 - 179 .

DOI: https://doi.org/10.5254/rct.12.88978

25. Ratnayake U.N. (2003). Ribbed smoked sheet. Handbook of Rubber Processing (eds. L.M.K. Tillekeratne, A. 
Nugawela \& W.M.G Seneviratne), pp. 15 - 32. Rubber Research Institute, Dartonfield, Agalawatte.

26. Ratnayake U.N., Kumara P.H.S., Siriwardena T.A.S., Prasad A.K.G.W. \& Rohanadeepa V.C. (2011). Effect of iron in processing water on quality of crepe rubber. Journal of the Rubber Research Institute of Sri Lanka 91: 1 - 14.

27. Rattanasom S., Prasertsri S. \& Ruangritnumchai T. (2009). Comparison of the mechanical properties at similar hardness level of natural rubber filled with various reinforcing-fillers. Polymer Testing 28(1): 8 - 12.

DOI: https://doi.org/10.1016/j.polymertesting.2008.08.004

28. Rezende C.A., Braganca F.C., Doi T.R., Lee L., Galembeck F. \& Baue F. (2010). Natural rubber-clay nanocomposites: mechanical and structural properties. Polymer 51(16): $3644-3652$.

DOI: https://doi.org/10.1016/j.polymer.2010.06.026

29. Rooj S., Stockelhuber K.W., Das A. \& Reuter U. (2012). Highly exfoliated natural rubber/clay composites by propping open procedure. Macromolecular Materials and Engineering 297(04): 369 - 383.

DOI: https://doi.org/10.1002/mame.201100185

30. Sanchez-Valdes S., Méndez-Nonell J., Ramos De Valle L.F., Lozano-Ramírez T., Ramírez-Vargas E., LópezQuintanilla M.L. \& Gutiérrez-Rodríguez J.M. (2009). Effect of different amine modified clays on the compatibility and clay dispersion of polypropylene nanocomposites. E-Polymers 9(1):1499 - 1514.

DOI: https://doi.org/10.1515/epoly.2009.9.1.1499

31. Sharif J., Yunus W.M.Z.W., Dahlan M., Zaman H.J. \& Ahmad M.H. (2005). Preparation and properties of radiation crosslinked natural rubber/clay nanocomposites.
Polymer Testing 24(2): 211 - 217.

32. Sun Y., Luo Y. \& Jia D. (2008). Preparation and properties of natural rubber composites with solid state organomodified montmorillonite. Polymer Science 107(5): 2786 - 2792.

33. Thomas S. \& Stephen R. (2010). Rubber Nanocomposites: Preparation, Properties and Application, pp. $169-171$. John Wiley and Sons, Inc., New York, USA. DOI: https://doi.org/10.1002/9780470823477

34. Uddin F. (2008). Nanoclays, and montmorillonite minerals. Metallurgical and Materials Transactions A 39(12): $2804-2814$.

DOI: https://doi.org/10.1007/s11661-008-9603-5

35. Vaia R.A., Ishii H. \& Giannelis E.P. (1993). Synthesis and properties of two-dimensional nanostructures by direct intercalation of polymer melts in layered silicates. Chemistry of Materials 5(12): 1694 - 1696. DOI: https://doi.org/10.1021/cm00036a004

36. Wang Y., Zhang H., Wu Y., Yang J. \& Zhang L. (2005). Preparation and properties of natural rubber/rectorite nanocomposites. Europian Polymer Journal 41(11): $2776-2783$.

DOI: https://doi.org/10.1016/j.eurpolymj.2005.05.019

37. Wu Y.P., Wang Y.Q., Zhang H.F., Wang Y.Z., Yu D.S., Zhang L.Q. \& Yang J. (2005). Rubber-pristine clay nanocomposites prepared by co-coagulating rubber latex and clay aqueous suspension. Composites Science and Technology 65(7): 1195 - 1202.

38. Zhong J., Li C., Li S., Kong Li., Yang L., Liao S. \& She X. (2009). Study on the properties natural rubber during maturation. Journal of Polymer Materials 26(03): $351-360$. 